Open Access

\title{
Metastasis-associated protein 1 (MTA1) is transferred by exosomes and contributes to the regulation of hypoxia and estrogen signaling in breast cancer cells
}

Bethany N. Hannafon ${ }^{1,2}$, Amy L. Gin ${ }^{1}$, Yi-Fan Xu' ${ }^{1}$ Matthew Bruns ${ }^{1}$, Cameron L. Calloway ${ }^{1}$ and Wei-Qun Ding ${ }^{1,2^{*}}$

\begin{abstract}
Background: Exosomes are small membrane-bound vesicles that contribute to tumor progression and metastasis by mediating cell-to-cell communication and modifying the tumor microenvironment at both local and distant sites. However, little is known about the predominant factors in exosomes that contribute to breast cancer (BC) progression. MTA1 is a transcriptional co-regulator that can act as both a co-activator and co-repressor to regulate pathways that contribute to cancer development. MTA1 is also one of the most up-regulated proteins in cancer, whose expression correlates with cancer progression, poor prognosis and increased metastatic potential.
\end{abstract}

Methods: We identified MTA1 in BC exosomes by antibody array and confirmed expression of exosome-MTA1 across five breast cancer cells lines. Ectopic expression of tdTomato-tagged MTA1 and exosome transfer were examined by fluorescent microscopy. CRISPR/Cas9 genetic engineering was implemented to knockout MTA1 in MCF7 and MDA-MB-231 breast cancer cells. Reporter assays were used to monitor hypoxia and estrogen receptor signaling regulation by exosome-MTA1 transfer.

Results: Ectopic overexpression of tdTomato-MTA1 in BC cell lines demonstrated exosome transfer of MTA1 to BC and vascular endothelial cells. MTA1 knockout in BC cells reduced cell proliferation and attenuated the hypoxic response in these cells, presumably through its co-repressor function, which could be rescued by the addition of exosomes containing MTA1. On the other hand, consistent with its co-activator function, estrogen receptor signaling was enhanced in MTA1 knockout cells and could be reversed by addition of MTA1-exosomes. Importantly, MTA1 knockout sensitized hormone receptor negative cells to 4-hydroxy tamoxifen treatment, which could be reversed by the addition of MTA1-exosomes.

Conclusions: This is the first report showing that BC exosomes contain MTA1 and can transfer it to other cells resulting in changes to hypoxia and estrogen receptor signaling in the tumor microenvironment. These results, collectively, provide evidence suggesting that exosome-mediated transfer of MTA1 contributes to BC progression by modifying cellular responses to important signaling pathways and that exosome-MTA1 may be developed as a biomarker and therapeutic target for BC.

Keywords: Exosomes, MTA1, Breast cancer

\footnotetext{
* Correspondence: weiqun-ding@ouhsc.edu

'Department of Pathology, University of Oklahoma Health Sciences Center,

975 NE 10th Street, BRC 411A, Oklahoma City, OK 73104, USA

${ }^{2}$ Peggy and Charles Stephenson Cancer Center, Oklahoma City, OK, USA
}

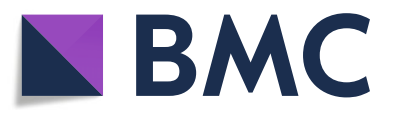

(C) The Author(s). 2019 Open Access This article is distributed under the terms of the Creative Commons Attribution 4.0 International License (http://creativecommons.org/licenses/by/4.0/), which permits unrestricted use, distribution, and reproduction in any medium, provided you give appropriate credit to the original author(s) and the source, provide a link to the Creative Commons license, and indicate if changes were made. The Creative Commons Public Domain Dedication waiver (http://creativecommons.org/publicdomain/zero/1.0/) applies to the data made available in this article, unless otherwise stated. 


\section{Background}

Exosomes are small $(50-100 \mathrm{~nm})$ secretory vesicles that mediate cell-to-cell communication in the tumor microenvironment by encapsulating and transferring cancer-promoting factors to surrounding cells or to distant sites through the circulation. Studies have demonstrated that breast cancer (BC) cells subjected to hypoxic conditions secrete exosomes in significantly greater numbers [1], and that exosomes shed from hypoxic BC cells promote focal adhesion formation, invasion, and metastasis [2], thus implicating that cancer exosomes are mediators of tumor metastasis. However, the predominant factors in exosomes that promote these processes are currently not fully understood.

The metastasis-associated proteins are a family of co-regulators comprised of MTA1, MTA2, and MTA3. MTA members are critical components of the nuclear remodeling and deacetylation (NuRD) complex and are primarily involved in regulating target gene expression through deacetylation of histones in chromatin [3]. As a major co-regulatory molecule MTA1 can quickly respond to physiological or developmental cues by altering gene expression in opposing directions. MTA1 is over-expressed in many cancers, including BC, and correlates with tumor metastasis and progression in human $\mathrm{BC}$ [4-8] and transgenic mouse models [9]. It is believed that the effects of MTA1 are due to its regulation of various cancer-promoting processes, including estrogen receptor signaling [10], canonical Wnt1/ $\beta$-catenin signaling [11], hypoxia-inducible factor- $1 \alpha$ (HIF-1 $\alpha$ ) stabilization $[12,13]$, and regulation of EMT via repression of E-cadherin and other adhesion molecules $[14,15]$. MTA1 is also involved in the DNA-damage response, and rapidly accumulates at sites of DNA damage [16]. Other studies have shown that MTA1 may have a variety of roles independent of the NuRD complex [8]. Despite these documented roles, specifically how MTA1 induces metastasis in cancer is unclear.

Using a cancer biomarker antibody array, we identified MTA1 protein in $\mathrm{BC}$ exosomes that may regulate hypoxia and estrogen signaling and contribute to $\mathrm{BC}$ progression. We characterized the exosome-mediated transfer and mechanistic role of exosome MTA1, by overexpression using fluorescent-tagged MTA1 protein and genetic loss of MTA1 using CRISPR/Cas9 genetic engineering methods. The role of exosome MTA1 on estrogen and hypoxia signaling mechanisms via exosome-mediated transfer were also investigated. This work indicates that exosome transfer of MTA1 protein may contribute to $\mathrm{BC}$ development and progression.

\section{Methods}

\section{Cell culture}

The normal human breast cell line MCF10A, and breast cancer cell lines MCF7, MDA-MB-231, ZR-75-1, BT20, and SK-BR-3 were obtained from the American Type
Culture Collection (Manassas, VA). The MCF7, MDAMB-231, ZR-75-1 and BT-20 cells were grown in DMEM medium supplemented with $10 \%$ fetal bovine serum (FBS), $100 \mathrm{IU} / \mathrm{mL}$ penicillin and $100 \mu \mathrm{g} / \mathrm{mL}$ streptomycin (Corning/ Mediatech, Inc. Manassas, VA). The MCF10A cells were cultured in DMEM/F12 supplemented with 5\% horse serum, $20 \mathrm{ng} / \mathrm{ml}$ epithelial growth factor, $0.5 \mathrm{mg} / \mathrm{ml}$ hydrocortisone, $100 \mathrm{ng} / \mathrm{ml}$ cholera toxin, $10 \mu \mathrm{g} / \mathrm{ml}$ insulin, $100 \mathrm{IU} / \mathrm{ml}$ penicillin, and $100 \mu \mathrm{g} / \mathrm{ml}$ streptomycin. SK-BR-3 cells were cultivated in McCoy's 5A medium supplemented with $10 \%$ FBS, $100 \mathrm{IU} / \mathrm{ml}$ penicillin and $100 \mu \mathrm{g} / \mathrm{ml}$ streptomycin. Exosome-depleted FBS and horse serum were prepared by pelleting the serum exosomes by ultracentrifugation at $100,000 \times g$ for $2 \mathrm{~h}$ at $4{ }^{\circ} \mathrm{C}$, and the resulting supernatant was filtered through a $0.2-\mu \mathrm{m}$ pore filter. Cells were routinely maintained in a humidified chamber at $37^{\circ} \mathrm{C}$ and $5 \% \mathrm{CO}_{2}$.

\section{Exosome isolation}

Exosomes were isolated by sequential centrifugation, filtration and ultracentrifugation as we have previously reported [17]. Exosome concentration was determined using the Pierce BCA protein assay (Thermo Fisher Scientific).

\section{Cancer biomarker antibody Array}

Exosome lysates from MCF7 cells were prepared, biotinylated, and incubated with the Cancer Biomarker Antibody Array (Cat. No. SCB200, Full Moon Biosciences) according to the manufacturer's instructions. The proteins were detected using Cy3-streptavidin (Thermo Fisher Scientific). Fluorescent intensity was measured at $532 \mathrm{~nm}$ on an Agilent Sure Scanner (Agilent Technologies). Fluorescent signal intensity was normalized to the mean of the positive control signal intensities according to the following equation: normalized signal intensity $=$ (mean signal intensity for protein $\mathrm{X}$ ) $\mathrm{x}$ (mean signal intensity of positive control on reference array)/mean signal intensity of positive control on array Y). Enriched gene ontology terms among proteins identified on antibody array were determined by the C5 GO gene set collection from the Molecular Signature Database v6.1 (MSigDB) [18] using the Gene Set Enrichment Analysis Software program [19].

\section{Stable expression of CD63 and MTA1}

The generation of MCF7 and MDA-MB-231 cells overexpressing GFP-tagged CD63 was previously reported [17]. The lentiviral vector pLV-Neo-CMV > ORF_1431bp:3xG GGGS:hMTA1[NM_004689.3] (lenti-CMV-tdTom-MTA1) used to overexpress tdTomato-tagged full length MTA1 isoform was constructed by VectorBuilder (Cyagen Biosciences). The vector ID is VB151117-10065, which can be used to retrieve detailed information about the vector on www.vectorbuilder.com. 


\section{Single guide RNA design and CRISPR/Cas9 knockout} The online guide design tool from DNA 2.0 gRNA (now known as ATUM, Newark, CA) was used to identify sgRNAs. The DNA sequence corresponding to the annotated stem loop miRNA (www.miRBase.org) was used as an input sequence. The highest scoring guides and/or those closest to the mature miRNA sequence were selected. Complementary oligos containing the sgRNA sequence and $B s m B I$ overhangs were synthesized (Integrated DNA Technologies), annealed, digested with $B s m B I$ and ligated into the lentiCRISPR v2, a gift from Feng Zhang (Addgene, \# 52961) [20]. MTA1-sgRNA-1: 5' - CTCCAAGGCCATCTCGGCG C-3'; MTA1-sgRNA-3: 5' - CAGCTGCGGCGCTCATGTG C-3 and MTA1-sgRNA-5: 5'-CTCTGTGGGCACCT TCGCAC-3'. MCF7 and MDA-MB-231 cells were infected with lentivirus in the presence of $8 \mu \mathrm{g} / \mathrm{ml}$ polybrene (Sigma-Aldrich). Approximately $48 \mathrm{~h}$ post-infection cells were selected by treating with $1 \mu \mathrm{g} / \mathrm{ml}$ puromycin (InvivoGen, San Diego, CA) for 3 days.

\section{Lentiviral transduction}

Lentiviral particles were produced similarly as before [17] using the 3rd generation packaging plasmids pMD2.G (Addgene plasmid \#12259); pMDL/ RRE g/p (Addgene plasmid \#12251) and pRSV-Rev (Addgene plasmid \#12253) were a gift from Didier Trono. The packaging plasmids were co-transfected with the lentiviral expression vector into human embryonic kidney $293 \mathrm{~T}$ cells using the polyethyleneimine (Polysciences Inc.) transfection method to produce replication deficient lentivirus. After 48 and $72 \mathrm{~h}$ of transfection, supernatants were pooled, filtered through a $0.45-\mu \mathrm{m}$ membrane and concentrated by ultracentrifugation at $100,000 \times \mathrm{g}$. MCF7 cells were infected with lentivirus in the presence of $8 \mu \mathrm{g} / \mathrm{ml}$ polybrene (Sigma-Aldrich). Approximately $48 \mathrm{~h}$ post-infection cells were selected by treating with $400 \mu \mathrm{g} / \mathrm{ml} \mathrm{G418}$ (InvivoGen, San Diego, CA) for 7 days.

\section{Genomic PCR, T7 endonuclease assay, and sanger sequencing}

Genomic DNA was extracted from wildtype and Cas9/ sgRNA transduced and puromycin selected MCF7 cells using the Pure Link Genomic DNA Mini-kit (Invitrogen) according to the manufacturer's protocol. Primers were designed to amplify a $\sim 800 \mathrm{bp}$ fragment surrounding the sgRNA cleavage site. MTA1 genomic primers: forward $5^{\prime}$ - CTTGGCCGACACTGTGGT-3' and reverse 5' - GACAGGAAGGACTATGGCGG-3'. The genomic loci of interest were amplified by PCR using Phusion High-Fidelity DNA Polymerase (Thermo-Scientific). The PCR amplicons were column purified using the MicroElute DNA cleanup Kit (Omega Bio-Tek). To assess the gene editing efficiency, the T7 Endonuclease assay was used. Briefly, $200 \mathrm{ng}$ of purified PCR product was diluted in 1X NEB Buffer 2 (New England Biolabs) and reannealed using the following conditions: denaturation at $95^{\circ} \mathrm{C}$ for $5 \mathrm{~min}$, re-annealing by ramping down the temperature to $85^{\circ} \mathrm{C}$ at a rate of $2^{\circ} \mathrm{C}$ per second, then from $85^{\circ} \mathrm{C}$ to $25^{\circ} \mathrm{C}$ at a rate of $0.1^{\circ} \mathrm{C}$ per second, and a final hold at $4{ }^{\circ} \mathrm{C}$. Ten units of T7 Endonuclease I (T7EI) (New England Biolabs) enzyme was added to the annealed PCR products and incubated at $37^{\circ} \mathrm{C}$ for $15 \mathrm{~min}$. The reaction was inhibited by adding $1.5 \mu \mathrm{l}$ of $0.25 \mathrm{M}$ EDTA. The T7EI digestion products were visualized by running on an Agilent Bioanalyzer DNA 1000 Chip (Agilent Technologies). Successful editing was determined by the presence of T7EI cleaved products in the Cas9/sgRNA transduced cells compared to wildtype cells. Single cell clones of each transduced cell line were expanded and sequenced for mutation pattern determination. The PCR amplicons of each clone were cloned into the $\mathrm{pCR}^{\mathrm{mm}} 4$ TOPO $^{\circ}$ TA vector (Thermo-Fisher). Random colonies were selected and sent for Sanger sequencing using the T7 primer (5'-TAATACGACTCACTATAGGG-3').

\section{Western blot}

Total cellular and exosome protein was prepared by re-suspending exosomes in RIPA buffer $(50 \mathrm{mM}$ Tris$\mathrm{HCl} \mathrm{pH} 7.4,150 \mathrm{mM} \mathrm{NaCl}, 0.5 \%$ sodium deoxycholate, $1 \%$ NP-40, and $0.1 \%$ sodium dodecyl sulfate) containing 1X protease inhibitor cocktail (Protease Inhibitor Mini Tablets, Pierce). About $30-50 \mu \mathrm{g}$ of protein was separated by SDS-PAGE (10\%), transferred to a PVDF membrane and blotted with antibodies against MTA1, $\mathrm{N}$-terminal (AB06723PU-N, OriGene), internal epitope (sc-17773, Santa Cruz Biotechnology), C-terminal epitope (5647, Cell Signaling Technology), GAPDH (20035, ProMab Biotechnologies, Richmond, CA), RFP (600-401-379, Rockland, Limerick, PA), and CD63 (sc-5275, Santa Cruz Biotechnology, Santa Cruz, CA).

\section{Luciferase reporter assays}

The estrogen response element luciferase reporter (3X ERE TATA luc) containing three copies of vitellogenin Estrogen Response Element was a gift from Donald McDonnell (Addgene plasmid \# 11354) [21]. The pGL3-HRE-luciferase reporter construct containing the hypoxia response elements (HRE) of the VEGF gene promoter was kindly provided by Dr. Konstantin Salnikow (Radiation Oncology Branch, NCI, Frederick, MD) [22]. MCF-7 and MDA-MB-231 cells were seeded into a 6-well plate and reached $70-80 \%$ confluence $24 \mathrm{~h}$ after plating. For estrogen signaling assay cells were plated in phenol-red free Improved Minimal Essential Media (IMEM) (Corning) supplemented with 5\% charcoal-stripped fetal bovine serum (GeneTex). The cells were then transfected with $2.5 \mu \mathrm{g} 3 \mathrm{X}$ ERE TATA luc or pGL3-HRE-luciferase along with the $1 \mu \mathrm{g}$ renilla luciferase expression plasmid (pRLTK) as a transfection control using the Lipofectamine 
3000 transfection reagent (Thermo Fisher Scientific) (16). The next day, cells were lifted and re-plated at a density of 10,000 cells per well in triplicate in white 96-well plate with or without exosomes. The following day the cells were treated with $150-300 \mu \mathrm{M}$ cobalt chloride hexahydrate dissolved in PBS or 5-10 nM 17 $\beta$-estradiol dissolved in ethanol (Sigma Aldrich) as appropriate. Approximately 16-24 h after treatment cells were lysed and assayed for luciferase activity using the Dual Luciferase Assay kit (Promega). Luminescence was detected on a Perkin Elmer Envision Multilabel reader. Data normalization was conducted by dividing firefly luciferase by renilla luciferase luminescence.

\section{RNA extraction and real-time PCR}

Total RNA from cultured cells was prepared using the TRIzol Reagent (Invitrogen/Thermo-Fisher) followed by a column clean-up using the PureLink RNA Mini Kit according to the manufacturer's protocol for whole transcriptome isolation (Invitrogen). RNA concentration was quantitated using the NanoDrop ND-100 Spectrophotometer (NanoDrop Technologies). Gene expression was measured by generating cDNA from 200 ng of total RNA using the iScript cDNA Synthesis kit (Bio-Rad, Hercules, CA). The synthesized cDNA was diluted in 2X iTaq Universal SYBR Green Supermix (Bio-Rad, Hercules, CA) and combined with $10 \mu \mathrm{M}$ of each forward and reverse primer. Specific primer sequences used are as follows: IGFBP4, forward 5' - AGCCCTCTG ACAAGGACGAG- $3^{\prime}$ and reverse $5^{\prime}$ - TCCGGTCTC GAATTTTGGCG-3'; SLC2A1, forward 5'CTGGCATCA ACGCTGTCTTC-3' and reverse 5'- GTTGACGAT ACCGGAGCCAA-3'; and the normalization control 36B4, forward 5'-ATCAACGGGTACAAACGAGTCCTG-3' and reverse 5'- AAGGCAGATGGATCAGCCAAGAAG-3'. PCR reactions were run on the Bio-Rad CFX 96 Real-Time PCR (Bio-Rad, Hercules, CA) instrument under the following conditions: hold at $95^{\circ} \mathrm{C}$ for $10 \mathrm{~min}$, then 40 cycles of 95 ${ }^{\circ} \mathrm{C}$ for $15 \mathrm{~s}$ and $60^{\circ} \mathrm{C}$ for $1 \mathrm{~min}$. Relative gene expression was assessed using the differences in normalized $\mathrm{Ct}(\Delta \Delta \mathrm{Ct}$ method) after normalization to 36B4.

\section{MTS cell proliferation assay}

Cells were seeded onto 96-well plate at a density of 12,000 cells/well in quadruplicate. The cells were cultured at $37{ }^{\circ} \mathrm{C}$ with $5 \% \mathrm{CO}^{2}$ for 4 days. For each well, the attached cells were incubated in $100 \mu \mathrm{L}$ growth medium supplemented with $20 \mu \mathrm{L}$ CellTiter $96^{\circ}$ AQueous One Solution (Promega, Madison, WI, USA) and incubated for $1 \mathrm{~h}$. The absorbance value at $495 \mathrm{~nm}$ was recorded using a spectrometer.

\section{Fluorescent microscopic imaging}

Cells co-expressing tdTom-MTA1 and CD63-GFP were grown on a glass coverslip to 50\% confluence. For co-culturing exosome uptake imaging $1 \times 10^{4}$ cells were plated in the upper chamber of a trans-well insert $\left(0.4 \mu \mathrm{m}\right.$ pore size) and $1 \times 10^{5} \mathrm{ZR}-75-1$ or EA.hy926 cells were plated on glass coverslips in the bottom chamber of a 24-well plate and cultured for 4 days. Cells were fixed with $4 \%$ paraformaldehyde for $15 \mathrm{~min}$. Coverslips with fixed cells were mounted on glass slides using ProLong Gold Antifade with DAPI (Thermo Fisher Scientific). Confocal images were collected on a Leica SP8 Confocal White Light Laser system microscope using a 40X objective. Fluorescent images were collected on a Nikon TE2000-E microscope using the 40X objective. For co-localization analysis, four regions of interest (ROI) were drawn over areas of tdTomato and GFP signal overlap. The average co-localization within the ROIs was calculated by measuring the pixel intensity-correlation by Pearson coefficient using the coloc2 plugin for Fiji/ImageJ software.

\section{Results}

\section{Breast cancer exosomes containing MTA1 promote} hypoxic response

As exosomes have been shown to promote cancer progression and metastasis, we examined the role of exosome transfer on activation of hypoxia signaling. A hypoxic state was induced with cobalt chloride in MCF10A and MCF7 cells and the hypoxic response was monitored using a hypoxic response element-driven luciferase reporter. With the addition of exosomes from the breast cancer cell line ZR-75-1, the hypoxic response was increased in both a dose- and time-dependent manner (Fig. 1a, b). To understand what specific cancer-related proteins were present in breast cancer exosomes that might promote this observed effect, exosomes were isolated from the conditioned media of the normal breast cell line MCF10A and the estrogen receptor positive breast cancer line MCF7. The isolated exosomes were verified by western blot, electron microscope, and nanoparticle analysis as we recently described [17, 23]. Exosome lysates were prepared and probed with a cancer biomarker array containing antibodies against 247 established cancer markers. Out of the 247 antibodies on the array, 77 resulted in a positive signal among both samples, 7 proteins were specifically present in MCF10A exosomes, 56 were specifically present in MCF7 exosomes, and 14 were detected in both samples (Additional file 1). After data normalization, of the 77 proteins detected 64 were significantly $(p<0.05)$ differentially expressed in MCF7 exosomes relative to MCF10A exosomes with a fold-change of 1.5 or greater. As expected, the proteins significantly over-expressed in MCF7 exosomes include cytokines, growth factors, proteases, cytokine and growth factor receptors, cell adhesion molecules, extracellular matrix and cytoskeletal proteins (Table 1). To determine enriched gene ontology (GO) terms among the detected MCF7 exosome proteins we performed Gene Set Enrichment Analysis. As shown in Table 2, the most overrepresented GO terms included "extracellular space", followed by "receptor binding", 


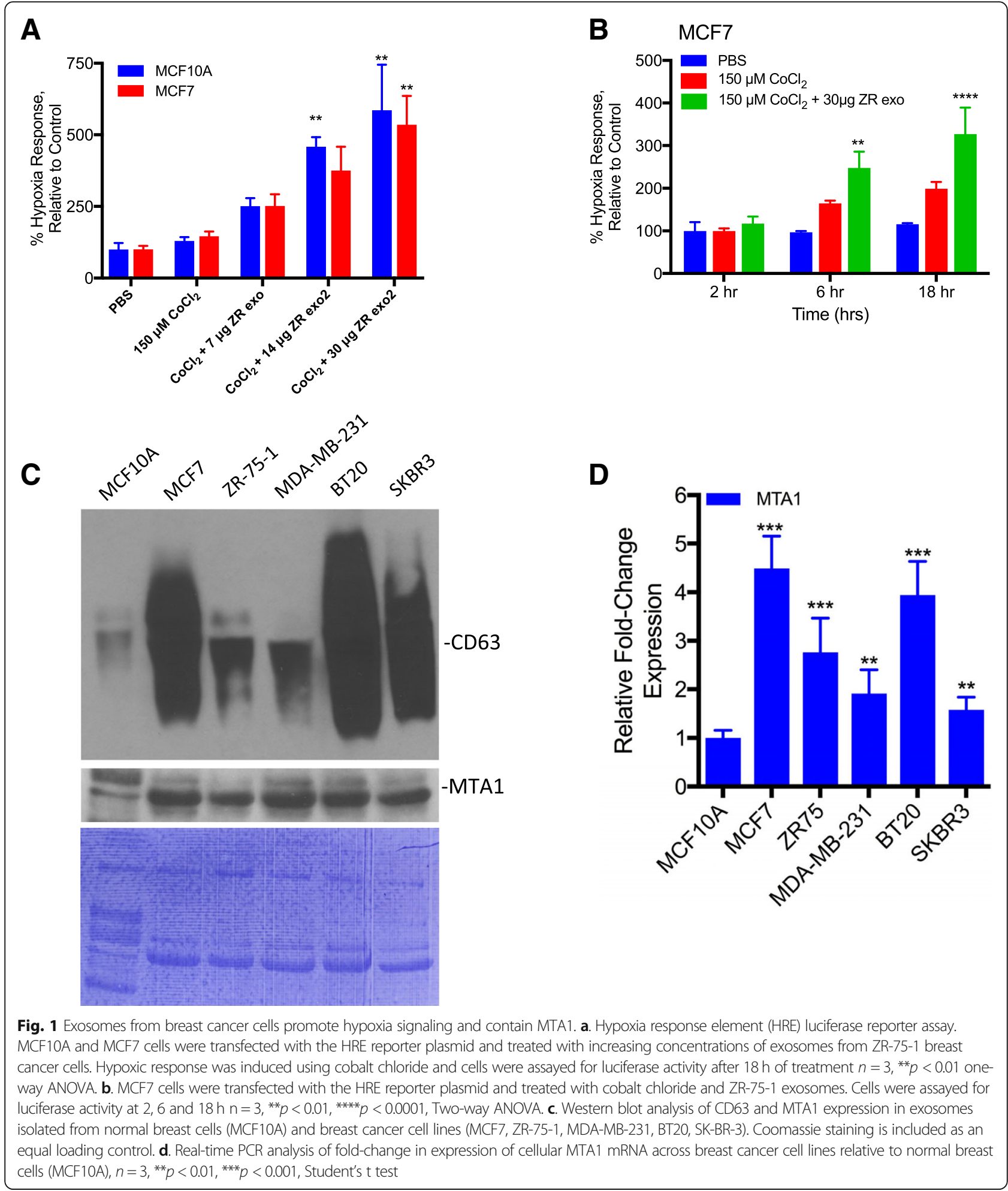

and "response to oxygen containing compound". Several of the proteins detected, however, were ascribed unexpected molecular functions including DNA binding proteins, transcription factors, and DNA repair proteins.
Among these molecules was metastasis associated protein 1 (MTA1) expressed 168-fold higher in MCF7 exosomes relative to MCF10A exosomes ( $p=1.51 \mathrm{E}-16)$. MTA1 is predominantly a nuclear protein that is one of the most upregulated protein in human cancers, and 
Table 1 Breast cancer exosome proteins identified by cancer biomarker antibody array. Proteins identified in either group with a fold-change $\geq 1.5$ (MCF7 vs. MCF10A), $p<0.05$ (Student's T test) are listed and grouped by molecular function

\begin{tabular}{|c|c|c|c|c|c|c|c|}
\hline Protein Name & Swiss Prot & Fold Change & $P$-value & Protein Name & Swiss Prot & Fold Change & P-value \\
\hline \multicolumn{4}{|c|}{ Signaling molecules (cytokines, growth factors, and peptide hormones) } & \multicolumn{4}{|l|}{ Cytoskeletal proteins } \\
\hline Myostatin & 014793 & $21,111.91$ & $2.29 \mathrm{E}-10$ & Tubulin gamma & P23258 & 754.10 & $1.93 \mathrm{E}-13$ \\
\hline FSH & P01225 & $15,362.78$ & 4.48E-11 & Tubulin beta & Q13509 & 450.98 & $6.32 \mathrm{E}-11$ \\
\hline IL-15 & P40933 & 8289.69 & $9.00 \mathrm{E}-12$ & Beta actin & & 2.77 & 2.80E-09 \\
\hline$|G F-| \mid$ & P01344 & 1935.77 & 4.89E-12 & Tubulin alpha & Q71U36 & 1.89 & $2.78 \mathrm{E}-02$ \\
\hline VEGFB & P49765 & 1535.45 & $1.51 \mathrm{E}-10$ & \multicolumn{4}{|l|}{ Protease inhibitor } \\
\hline IL-12 & P29459 & 1072.56 & 1.28E-09 & $\mathrm{ACT}$ & P01011 & 1573.14 & 2.07E-11 \\
\hline MIP-3ß/CCL19 & Q99731 & 838.61 & $1.36 \mathrm{E}-12$ & TIMP-1 & P01033 & 1296.86 & 2.69E-10 \\
\hline TGF $\beta 2$ & P61812 & 691.68 & $7.88 \mathrm{E}-15$ & PAI-1/SERPINE1 & P05121 & 0.00007 & 1.50E-08 \\
\hline PDGFB & P01127 & 365.81 & $8.82 \mathrm{E}-13$ & \multicolumn{4}{|l|}{ DNA Binding Protein } \\
\hline Mammaglobin B & O75556 & 285.27 & 7.06E-04 & MLL/KMT2A & Q03164 & 402.38 & $6.22 \mathrm{E}-17$ \\
\hline Osteopontin & P10451 & 262.26 & 7.16E-04 & $\mathrm{MSH} 2$ & P43246 & 175.50 & $1.15 \mathrm{E}-12$ \\
\hline IL-17E & Q9H293 & 226.68 & $1.56 \mathrm{E}-12$ & MTA1 & Q13330 & 168.22 & $1.51 \mathrm{E}-16$ \\
\hline |GF-I & P05019 & 174.44 & 4.99E-02 & \multicolumn{4}{|c|}{ Cell Adhesion Molecules } \\
\hline IL-17F & Q96PD4 & 171.53 & $1.00 \mathrm{E}-11$ & CEA & P06731 & 4423.56 & 1.96E-11 \\
\hline TNF-alpha & P01375 & 107.92 & 5.67E-04 & VCAM-1 & P19320 & 573.18 & 4.07E-11 \\
\hline TGF alpha & P01135 & 81.47 & 4.95E-02 & ALCAM & Q13740 & 344.25 & $3.76 \mathrm{E}-14$ \\
\hline IL-13 & P35225 & 0.0004 & $1.02 \mathrm{E}-02$ & ITGB2/CD18 & P05107 & 0.12 & $1.31 \mathrm{E}-03$ \\
\hline NGF & P01138 & 0.08 & $6.23 \mathrm{E}-13$ & TSP1 & P07996 & 0.03 & 1.05E-15 \\
\hline Resistin & Q9HD89 & 0.05 & 8.90E-13 & \multicolumn{4}{|l|}{ Transfer/Carrier Protein } \\
\hline RANTES/CCL5 & P13501 & 0.0002 & $3.28 \mathrm{E}-10$ & ALB & P02768 & 165.05 & 3.77E-12 \\
\hline EGF & P01133 & 0.0002 & 5.66E-04 & AFP & P02771 & $14,293.40$ & $3.98 \mathrm{E}-11$ \\
\hline \multicolumn{4}{|l|}{ Hydrolase/Protease } & \multicolumn{4}{|c|}{ Extracellular Matrix Protein } \\
\hline PSA & P07288 & 7771.26 & $5.22 \mathrm{E}-15$ & COL4A1 & P02462 & 2326.71 & 2.49E-06 \\
\hline MMP-10 & P09238 & 7395.53 & 1.10E-10 & Laminin & & 387.50 & $1.24 \mathrm{E}-13$ \\
\hline MMP-2 & P08253 & 4044.93 & $2.41 \mathrm{E}-06$ & COL3A1 & P02461 & 320.58 & $3.22 \mathrm{E}-09$ \\
\hline MMP-19 & Q99542 & 298.36 & $3.60 \mathrm{E}-11$ & ITGA5 & P08648 & 131.46 & $9.71 \mathrm{E}-12$ \\
\hline MMP-7 & P09237 & 186.87 & 1.07E-02 & Fibronectin & P02751 & 0.26 & $8.82 \mathrm{E}-13$ \\
\hline MMP-11 & P24347 & 42.32 & 1.10E-10 & \multicolumn{4}{|l|}{ Oxidoreductase } \\
\hline Cytokine receptor & & & & MPO & P05164 & 419.24 & $3.16 \mathrm{E}-10$ \\
\hline TGFBR3 & Q03167 & 902.09 & 3.53E-09 & \multicolumn{4}{|c|}{ Defense/Immunity Protein } \\
\hline TGFBR2 & P37173 & 295.19 & $1.09 \mathrm{E}-08$ & B2M & P61769 & 0.060 & $8.91 \mathrm{E}-13$ \\
\hline IL2RA & P01589 & 0.01 & $6.00 \mathrm{E}-10$ & $\lg A$ & & 0.067 & $8.99 \mathrm{E}-11$ \\
\hline \multicolumn{4}{|l|}{ Growth Factor Receptor } & \multicolumn{4}{|l|}{ Storage Protein } \\
\hline CD40LR & P25942 & 519.22 & $1.08 \mathrm{E}-12$ & Ferritin & P02794 & 1414.57 & $3.53 \mathrm{E}-13$ \\
\hline Tek/Tie2 & Q02763 & 402.05 & $1.21 \mathrm{E}-10$ & \multicolumn{4}{|l|}{ Transcription Factor } \\
\hline TYRO3 & Q06418 & 245.33 & $5.91 \mathrm{E}-04$ & THR alpha & P10827 & 1164.74 & $1.75 \mathrm{E}-14$ \\
\hline NTRK1/TrkA & P04629 & 236.47 & $6.48 \mathrm{E}-14$ & \multicolumn{4}{|l|}{ Transferase/Kinase } \\
\hline \multirow[t]{3}{*}{ PDGFR alpha } & P16234 & 204.86 & $5.11 \mathrm{E}-11$ & Tyk2 & P29597 & $15,893.91$ & $8.85 \mathrm{E}-16$ \\
\hline & & & & \multicolumn{4}{|l|}{ DNA Repair Protein } \\
\hline & & & & MUM1 & Q2TAK8 & 632.43 & $5.45 \mathrm{E}-04$ \\
\hline
\end{tabular}


Table 2 Enriched Gene Ontology Terms for MCF7 Exosome Proteins

\begin{tabular}{|c|c|c|c|c|c|}
\hline Gene Set Name & \# Genes in Gene Set (K) & \# Genes in Overlap (k) & $\mathrm{k} / \mathrm{K}$ & $p$-value & FDR q-value \\
\hline GO_EXTRACELLULAR_SPACE & 1376 & 44 & 0.032 & $3.80 \mathrm{E}-48$ & $2.25 \mathrm{E}-44$ \\
\hline GO_RECEPTOR_BINDING & 1476 & 42 & 0.0285 & $1.61 \mathrm{E}-43$ & $4.76 \mathrm{E}-40$ \\
\hline GO_RESPONSE_TO_OXYGEN_CONTAINING_COMPOUND & 1381 & 40 & 0.029 & $1.82 \mathrm{E}-41$ & $3.58 \mathrm{E}-38$ \\
\hline GO_POSITIVE_REGULATION_OF_RESPONSE_TO_STIMULUS & 1929 & 42 & 0.0218 & $1.03 \mathrm{E}-38$ & $1.53 \mathrm{E}-35$ \\
\hline GO_RESPONSE_TO_EXTERNAL_STIMULUS & 1821 & 41 & 0.0225 & $3.14 \mathrm{E}-38$ & $3.72 \mathrm{E}-35$ \\
\hline GO_REGULATION_OF_CELL_PROLIFERATION & 1496 & 38 & 0.0254 & $5.24 \mathrm{E}-37$ & $5.16 \mathrm{E}-34$ \\
\hline GO_CELLULAR_RESPONSE_TO_ORGANIC_SUBSTANCE & 1848 & 40 & 0.0216 & $1.72 \mathrm{E}-36$ & $1.45 \mathrm{E}-33$ \\
\hline GO_CYTOKINE_RECEPTOR_BINDING & 271 & 24 & 0.0886 & $1.01 E-35$ & $7.49 \mathrm{E}-33$ \\
\hline GO_IMMUNE_SYSTEM_PROCESS & 1984 & 38 & 0.0192 & 1.85E-32 & $1.09 \mathrm{E}-29$ \\
\hline GO_REGULATION_OF_CELLULAR_COMPONENT_MOVEMENT & 771 & 29 & 0.0376 & $1.85 \mathrm{E}-32$ & 1.09E-29 \\
\hline
\end{tabular}

Gene Set Enrichment Analysis

To cite your use of the GSEA software, please reference Subramanian, Tamayo, et al. (2005, PNAS 102, 15545-15550) and Mootha, Lindgren, et al. (2003, Nat Genet $34,267-273)$

associated with cancer progression [24]. In addition, MTA1 is known to regulate the hypoxia response by stabilizing HIF-1 [13]. We isolated exosomes from the normal breast cell line MCF10A, and 5 breast cancer cells lines. Exosome isolation was confirmed by detection of CD63 (a marker of exosomes) using western blot. Importantly, MTA1 was detected in exosomes derived from all 5 breast cancer cell lines including MCF7, ZR-75-1, MDA-MB-231, BT-20, and SK-BR-3 as analyzed by western blot (Fig. 1c). Cellular expression of MTA1 was analyzed by qRT-PCR (Fig. 1d). These results are the first to describe MTA1 in breast cancer exosomes and the elevated levels of exosome MTA1 are consistent with reports of MTA1 expression in cancer [4-8]. We then focused on characterization of the transfer and function of exosome MTA1 in our model systems.

\section{Exosome MTA1 is transferred to other cells}

We previously generated MCF7 (ER positive) and MDA-MB-231 (triple negative) breast cancer cell lines that stably express GFP-tagged CD63, a general surface marker of exosomes [17]. To visualize and track MTA1 secreted in exosomes from breast cancer cells a lentiviral vector was constructed containing tdTomato fused to MTA1 via a 3xGGGGS linker under the control of a CMV promoter (CMV-tdTom-MTA1). The CMV-tdTom-MTA1 lentiviral particles were transduced to the CD63-GFP-MCF7 and CD63-GFP-MDA-MB-231 cells. Overexpression of tdTomato-tagged MTA1 was confirmed by confocal microscopy (Fig. 2a) and western blot (Fig. 2b). The effect of tdTom-MTA1 overexpression in MCF7 and MDA-MB-231 on cell proliferation was measured. As shown in Fig. 2c, tdTom-MTA1 expression did not significantly affect the rate of proliferation of MCF7 cell lines, however the proliferation of the MDA-MB-231 cells was slightly reduced at 3 days of growth (Fig. 2c). In a trans-well co-culture system exosomemediated transfer of MTA1 from MCF7 and MDA-MB-231 cells expressing GFP-CD63 and tdTom-MTA1 to ZR-75-1 (breast cancer cells) and EA.hy926 (vascular endothelial cells) was observed by fluorescent microscopy. As shown in Fig. 2d, co-localization of the green fluorescence (CD63GFP) and red-fluorescence (tdTom-MTA1) is observed in both ZR-75-1 and EA.hy926 cells. The overlap of the green and red colors was quantified (Fig. 2e). Furthermore western blot confirmed the uptake of RFP (tdTom) and MTA1 by EA.hy926 and ZR-75-1 cells (Fig. 2f). These results demonstrate that MTA1 is secreted via exosomes and can be taken up by other cells.

\section{MTA1 CRISPR/Cas9 knockout in breast cancer cells}

In order to understand whether exosome-MTA1 contributes to breast cancer progression/metastasis, genetic knockouts of MTA1 in MCF7 and MDA-MB-231 cells were generated using a CRISPR/Cas9 expression system carrying a small guide RNA (sgRNA) targeted to MTA1. Three to five sgRNAs were designed and ligated into the lentiCRISPR v2 vector and lentiviral particles expressing Cas9 and MTA1-sgRNAs were generated and transduced to MCF7 and MDA-MB-231 cells. A T7 endonuclease assay was conducted to determine cleavage efficiency of each sgRNA. Bioanalyzer results indicated that DNA cleavage occurred with each sgRNA introduced to the cells relative to wildtype cells (Fig. 3a). After puromycin selection, MTA1-KO-MCF7 and MTA1-KO-MDA-MB-231 clones were generated and knockout was confirmed (3 clones per cell line) by western blot (Fig. 3b). Cell proliferation was significantly reduced in each MTA1 knockout breast cancer cell line relative to wildtype control cells (Fig. 3c).

\section{Exosome MTA1 regulates hypoxic response}

As MTA1 is known to positively regulate hypoxia signaling, we sought to determine whether MTA1 overexpression or MTA1 knockout affects the hypoxic response. MCF7 wildtype, MCF7 MTA1-knockout, MDA-MB-231 


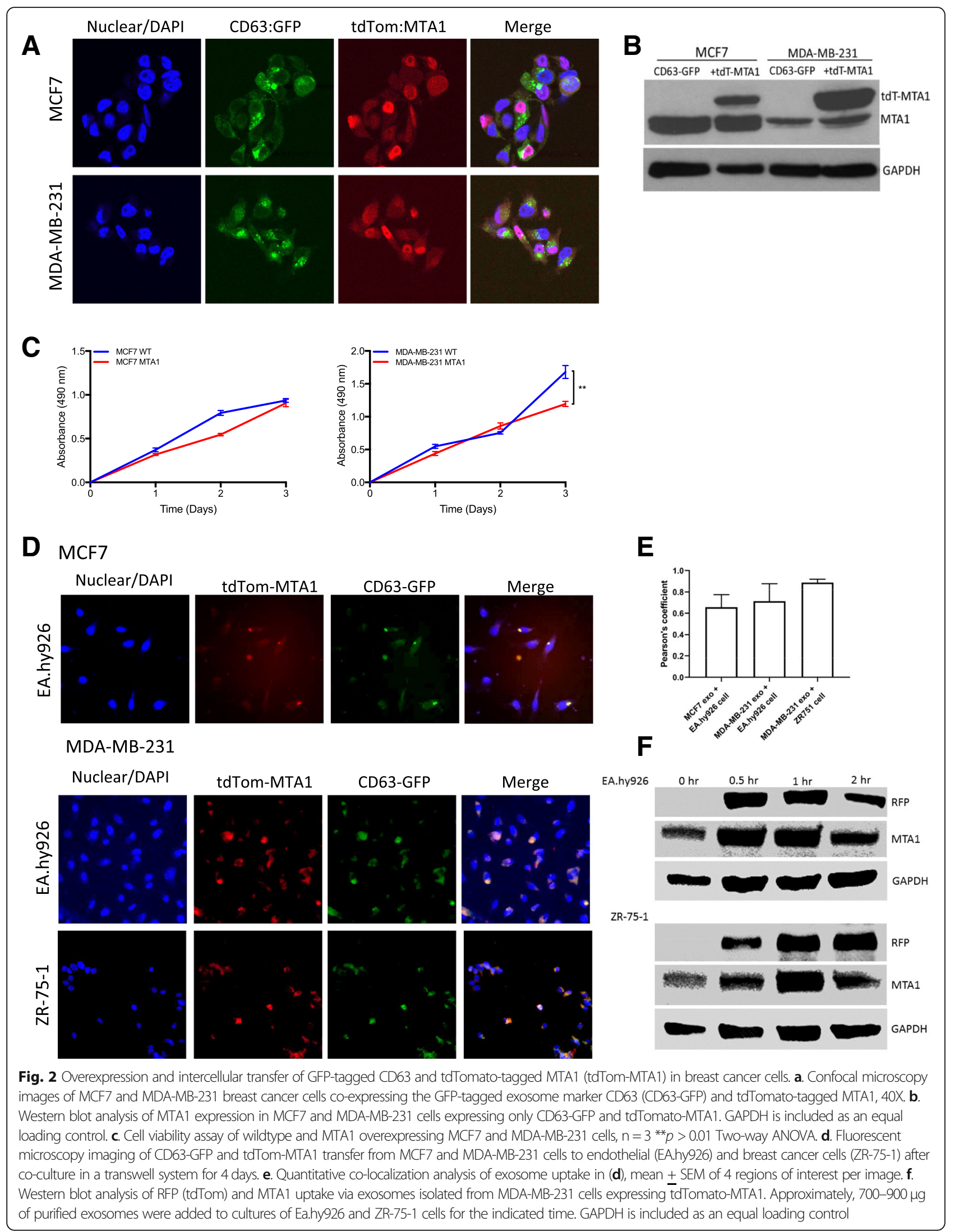




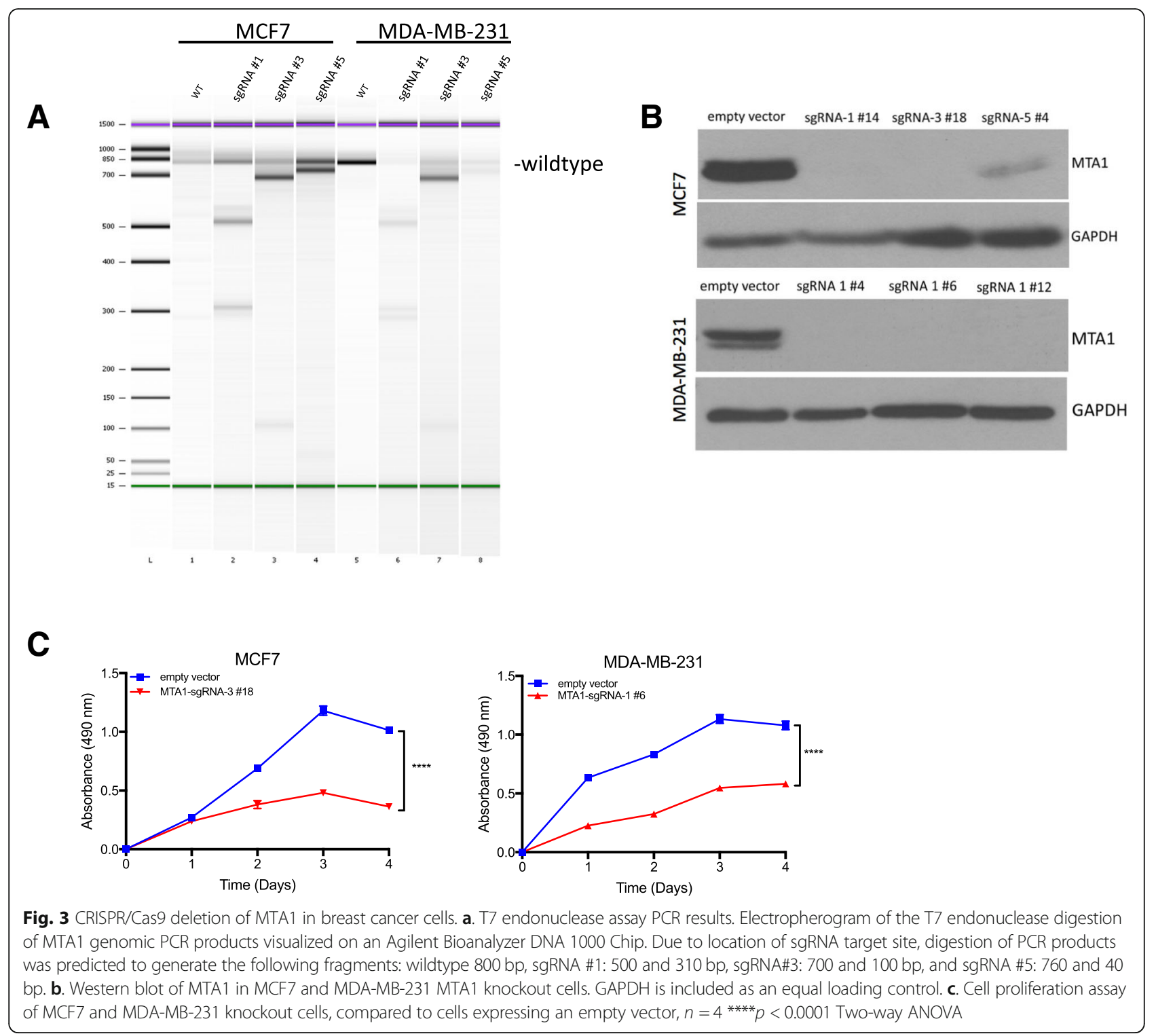

wildtype and MDA-MB-231 MTA1-knockout cells were transfected with the hypoxia response element (HRE) reporter and treated with cobalt chloride for $24 \mathrm{~h}$. The hypoxic response was significantly attenuated in the knockout cells relative to wildtype breast cancer cells (Fig. 4a, b). However, when purified exosomes from MTA1 overexpressing cells were pre-incubated with wildtype and MTA1 knockout cells the hypoxic response increased significantly, whereas the addition of exosomes alone (without cobalt) had no effect (Fig. 4d, e). A similar response was observed when MDA-MB-231 cells were exposed to hypoxia (1\%) using a hypoxic chamber (Fig. 4c, f).

\section{Exosome MTA1 regulates estrogen response}

Through its interaction with histone deacetylase and the nucleosome remodeling complex, MTA1 can block the ability of estradiol to stimulate estrogen receptor-mediated transcription [10]. Therefore, we sought to determine if exosome transfer of MTA1 could also attenuate estrogen signaling. The estrogen response element luciferase reporter was expressed in MCF7 wildtype, MCF7 tdTom-MTA1, and MCF7 MTA1-knockout cells. As expected, upon stimulation with $17 \beta$-estradiol (E2), estrogen response was increased in MCF7 wildtype cells. The estrogen response was attenuated in MCF7 MTA1 overexpressing cells, while the estrogen response was significantly increased in MTA1-knockout cells as measured by luciferase reporter assay (Fig. 5a). Likewise, the expression of the estrogen signaling target genes IGFBP4 and SLC2A1 were significantly attenuated in the MTA1 overexpressing cells and in the MTA1-knockout cells expression levels were similar to the MCF7 wildtype cells (Fig. 5b, upper). Silencing of MTA1 in estrogen receptor negative cells 


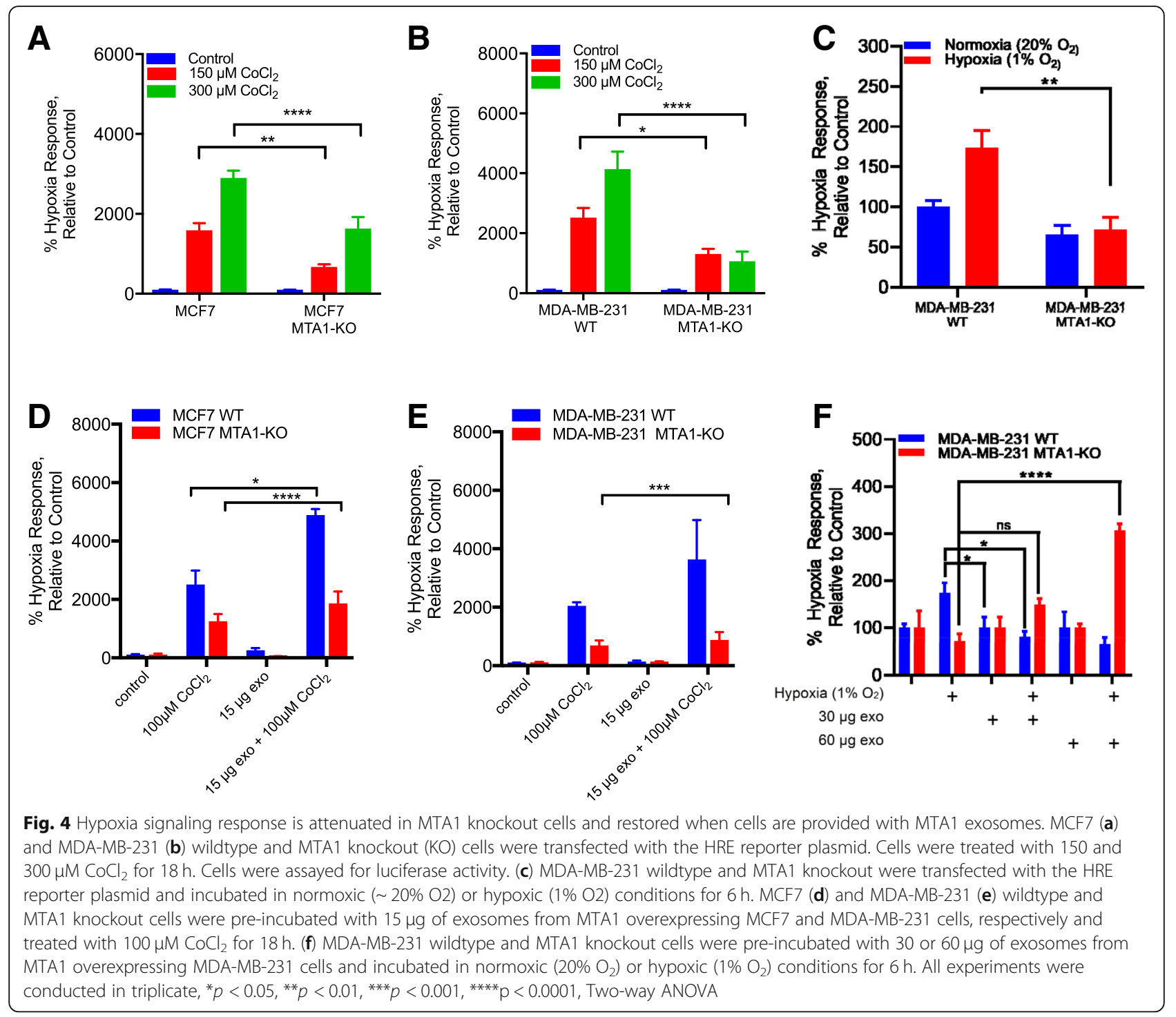

has been shown to increase the expression of estrogen receptor $\alpha$, enhance estrogen receptor signaling, and sensitize them to tamoxifen treatment [25]. Indeed, the expression of IGFBP4 and SLC2A1 were both significantly increased in MDA-MB-231 MTA1 knockout cells relative to MDA-MB-231 wildtype cells upon stimulation with E2 (Fig. 5b, lower). When wildtype and MTA1-knockout cells were preincubated with exosomes from MTA1 overexpressing cells, the estrogen signaling response was attenuated in both MCF7 wildtype and MTA1-knockout cells (Fig. 5c). MDA-MB-231 MTA1-knockout cells were also more sensitive to 4-hydroxytamoxifen (4-OHT) treatment than wildtype MDA-MB-231 cells (Fig. 5d). This effect could be rescued by the addition of exosomes from MTA1 overexpressing cells. (Fig. 5e). These results indicate that exosome transfer of MTA1 effects estrogen signaling response and can influence cellular response to anti-estrogen therapies.

\section{Discussion}

The role of exosomes in cancer progression has been heavily investigated in recent years, however the predominant factors present in exosomes that may contribute to cancer development and progression via intercellular communication are not well understood. In this study, we identified many proteins in breast cancer exosomes that may contribute to breast cancer progression and specifically characterized the process and biological consequence of exosome transfer of MTA1 in breast cancer cells. We found that MTA1 is transferred through exosomes, and that exosome transfer of MTA1 alters hypoxic and estrogen signaling.

Due to its widespread overexpression in human cancers and its dual co-repressor and co-activator functions, MTA1 is considered a master regulatory molecule capable of regulating many pathways that are critical to cancer development and progression [8]. We demonstrated 
A

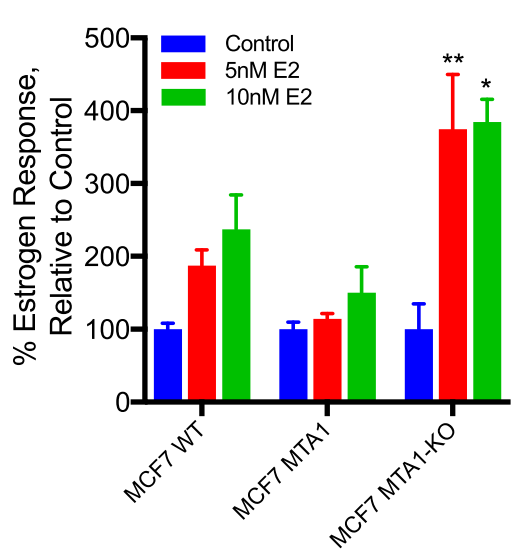

C

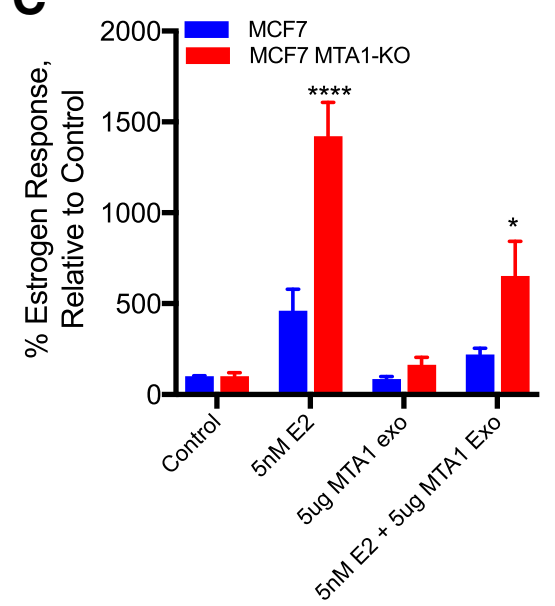

E

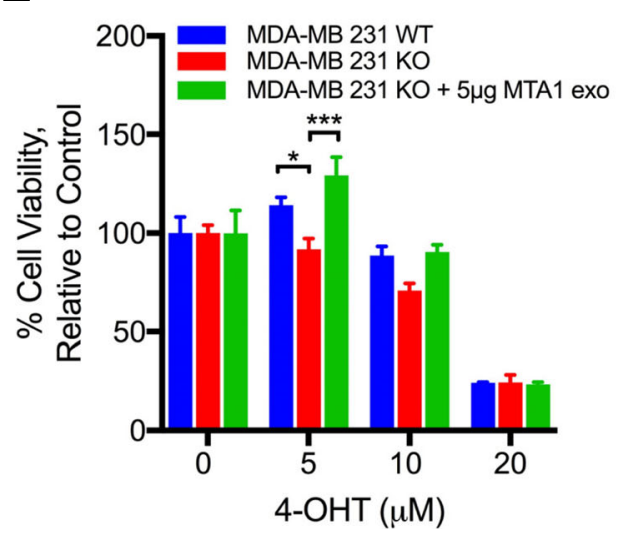

B
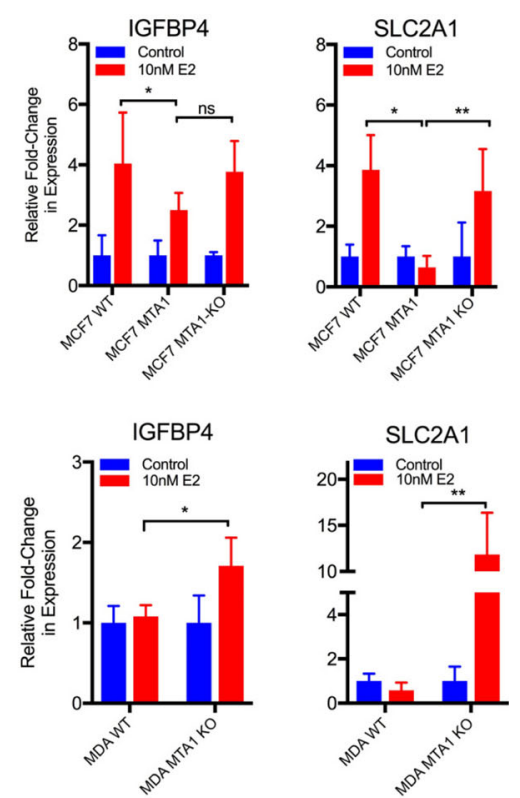

D

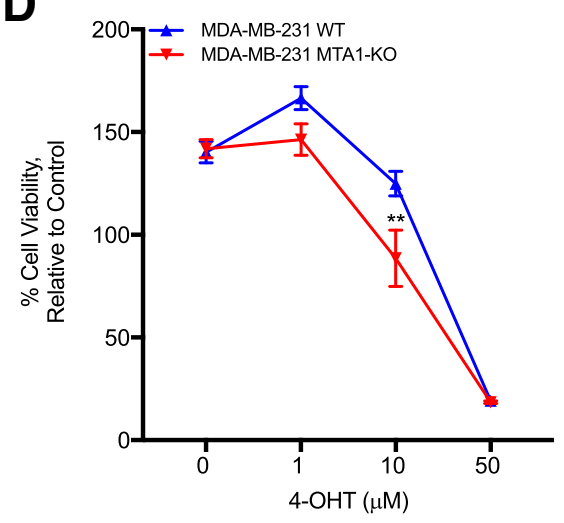

Fig. 5 (See legend on next page.) 
(See figure on previous page.)

Fig. 5 MTA1 knockout in breast cancer affects estrogen signaling and tamoxifen sensitivity that can be attenuated by the addition of MTA1 exosomes. a MCF7 wildtype, tdTom-MTA1, and MTA1 knockout $(K O)$ cells were transfected with estrogen response luciferase reporter plasmid and treated with 5 or $10 \mathrm{nM}$ 17ß-estradiol (E2). After 24-h incubation cells were assayed for luciferase activity, $n=3,{ }^{*} p<0.05,{ }^{* *} p<0.01$, Two-way ANOVA. b Real-time PCR analysis of IGFBP4 and SLC2A1 estrogen response gene expression in wildtype, tdTom-MTA1, and MTA1-KO cells. Cells were grown in phenol-red free medium supplemented with charcoal-stripped serum for 2 days. Cells were treated with $10 \mathrm{nM}$ E2 for $24 \mathrm{~h}, \mathrm{n}=3,{ }^{*} p<0.05$, ${ }^{* *} p<0.01$, Student's $t$ test. c MCF7 wildtype and MTA1-KO cells were transfected with estrogen luciferase reporter and pre-incubated with $5 \mu \mathrm{gg}$ of exosomes from tdTomMTA1 MCF7 cells. Cells were treated with $5 \mathrm{nM}$ E2 and assayed for luciferase activity after $24 \mathrm{~h}, \mathrm{n}=3,{ }^{*} p<0.05,{ }^{* * * *} p<0.0001$, Two-way ANOVA. d Cell viability assay of MDA-MB-231 wildtype and MTA1 KO cells treated with 4-hydroxytamoxifen (4-OHT) at the indicated doses for $72 \mathrm{~h}, n=3,{ }^{* *} p<0.01$, Two-way ANOVA. e Cell viability assay of MDA-MB-231 wildtype and MTA1 KO cells were pre-incubated with $5 \mu \mathrm{g}$ of MTA1 exosomes and then treated with 4-hydroxytamoxifen (4-OHT) at the indicated doses for $72 \mathrm{~h}, \mathrm{n}=3,{ }^{*} \mathrm{p}<0.05$, ${ }^{* * *} p<0.001$, Two-way ANOVA

that MTA1 can be transferred via exosomes from breast cancer cells to neighboring cells and can activate or repress signaling pathways that are known to promote cancer progression. The transfer of MTA1 through breast cancer exosomes was initially revealed by a well-designed antibody array and confirmed by western blot analysis that detected MTA1 expression in exosomes derived from breast cancer cells. Definitive evidence of exosome MTA1 transfer was obtained using a co-culture model system in which a florescent-tagged MTA1 was expressed in breast cancer cells and transferred to breast cancer cells and endothelial cells. These observations indicate that even nuclear proteins can be transferred through exosomes and participate in exosome-mediated intercellular communication. Consistent with its co-activator function, exosome MTA1 was able to increase hypoxia signaling in breast cancer cells as analyzed by a reporter gene assay. Given the significance of hypoxic signaling in breast cancer, this observation strongly suggests an important role of exosome MTA1 in breast cancer progression. In line with its co-repressor function, we found that exosome MTA1 increases estrogen receptor signaling and affects tamoxifen sensitivity in triple-negative breast cancer cells, demonstrating the dual nature of this protein and the potential effect of exosome transfer of MTA1 in the tumor microenvironment. Exosome MTA1 may have to enter nucleus to alter estrogen receptor-dependent transcription. Alternatively it might suppress estrogen receptor signaling by blocking the receptor from entering nucleus. Further investigation is warranted to answer this question.

Because of its diverse roles, MTA1 is an attractive drug target, although currently no drug has been designed to specifically target MTA1. However, inhibitors that disrupt MTA1 interactions with crucial binding partners, such as histone deacetylase 1 (HDAC-1) [26, 27], have been shown to reduce metastasis and MTA1 expression in cancer cell lines and animal models [28]. The results from the present study indicate that exosome MTA1 could contribute to breast cancer progression by regulating important signaling pathways and thus may serve as a therapeutic target for the management of this malignancy. In addition, because exosomes can be isolated from various body fluids it would be of great interest to determine whether MTA1 is present in exosomes isolated from the blood of breast cancer patients or other cancer patients in general, serving as circulating biomarker for diagnosis or prognosis.

\section{Conclusions}

This is the first study to have identified the nuclear factor MTA1 in breast cancer exosomes, demonstrated the transfer of MTA1 through exosomes, and characterized how exosome MTA1 affects cancer signaling pathways. This work suggests that exosome-mediated transfer of MTA1 is a significant driving force behind breast cancer progression and that targeting exosome MTA1 signaling or activity are potential therapeutic strategies for breast cancer management.

\section{Additional file}

Additional file 1: Raw and normalized fluorescent intensity data. File contains the raw and normalized fluorescent intensity data from the Cancer Biomarker Antibody array. (XLSX 441 kb)

\section{Abbreviations}

4-OHT: Hydroxytamoxifen, E2,17ß-estradiol; CRISPR: Clustered regularly interspaced short palindromic repeats; ERE: Estrogen response element; HDAC-1: Histone deacetylase 1; HIF-1a: Hypoxia-inducible factor-1a; HRE: Hypoxia response element; KO: Knockout; MTA1: Metastasis-associated protein 1; NuRD: Nuclear remodeling and deacetylation; sgRNA: Small guide RNA

\section{Acknowledgements}

The Functional Genomics Core at the University of Oklahoma Stephenson Cancer Center supported this study. This core was supported by the National Cancer Institute Cancer Center Support Grant P30CA225520. The content of this manuscript is solely the responsibility of the authors and does not necessarily represent the official views of the National Institutes of Health. We thank the Laboratory for Molecular Biology and Cytometry Research at OUHSC which provided fluorescent confocal microscopic imaging services.

\section{Funding}

This research was supported by grants from the Oklahoma Center for the Advancement of Science and Technology (HR14-147), the Oklahoma Shared Clinical and Translational Resources (NIGMS \#U54GM104938), and the Presbyterian Health Foundation.

\section{Availability of data and materials}

The data generated or analyzed during this study are included in this published article and its supplementary information files or are available from the corresponding author on reasonable request. 


\section{Authors' contributions}

BNH designed the study, carried out and/or supervised the experiments and drafted the manuscript. AG, MB and CLC assisted with in vitro cellular assays and western blot. YFX assisted with molecular cloning and related knockout experiments. WQD conceived of the study and participated in its design and coordination and helped to draft the manuscript. All authors read and approved the final manuscript.

\section{Ethics approval and consent to participate}

Not applicable.

\section{Consent for publication}

All authors have read this manuscript and approved for the submission.

\section{Competing interests}

The authors declare that they have no competing interests.

\section{Publisher's Note}

Springer Nature remains neutral with regard to jurisdictional claims in published maps and institutional affiliations.

\section{Received: 17 August 2018 Accepted: 8 February 2019}

Published online: 19 February 2019

\section{References}

1. King HW, Michael MZ, Gleadle JM. Hypoxic enhancement of exosome release by breast cancer cells. BMC Cancer. 2012;12:421

2. Wang T, Gilkes DM, Takano N, Xiang L, Luo W, Bishop CJ, Chaturvedi P, Green JJ, Semenza GL. Hypoxia-inducible factors and RAB22A mediate formation of microvesicles that stimulate breast cancer invasion and metastasis. Proc Natl Acad Sci U S A. 2014;111(31):E3234-42.

3. Manavathi B, Kumar R. Metastasis tumor antigens, an emerging family of multifaceted master coregulators. J Biol Chem. 2007;282(3):1529-33.

4. Toh Y, Nicolson GL. The role of the MTA family and their encoded proteins in human cancers: molecular functions and clinical implications. Clin Exp Metastasis. 2009;26(3):215-27.

5. Jang KS, Paik SS, Chung H, Oh YH, Kong G. MTA1 overexpression correlates significantly with tumor grade and angiogenesis in human breast cancers. Cancer Sci. 2006:97(5):374-9.

6. Martin MD, Hilsenbeck SG, Mohsin SK, Hopp TA, Clark GM, Osborne CK, Allred DC, O'Connell P. Breast tumors that overexpress nuclear metastasisassociated 1 (MTA1) protein have high recurrence risks but enhanced responses to systemic therapies. Breast Cancer Res Treat. 2006;95(1):7-12.

7. Zhu X, Guo Y, Li X, Ding Y, Chen L. Metastasis-associated protein 1 nuclear expression is associated with tumor progression and clinical outcome in patients with non-small cell lung cancer. J Thorac Oncol. 2010;5(8):1159-66.

8. Li DQ, Pakala SB, Nair SS, Eswaran J, Kumar R. Metastasis-associated protein $1 /$ nucleosome remodeling and histone deacetylase complex in cancer. Cancer Res. 2012;72(2):387-94.

9. Zhang H, Stephens LC, Kumar R. Metastasis tumor antigen family proteins during breast cancer progression and metastasis in a reliable mouse model for human breast cancer. Clin Cancer Res. 2006;12(5):1479-86.

10. Mazumdar A, Wang RA, Mishra SK, Adam L, Bagheri-Yarmand R, Mandal M, Vadlamudi RK, Kumar R. Transcriptional repression of oestrogen receptor by metastasis-associated protein 1 corepressor. Nat Cell Biol. 2001:3(1):30-7.

11. Li DQ, Pakala SB, Reddy SD, Ohshiro K, Peng SH, Lian Y, Fu SW, Kumar R. Revelation of p53-independent function of MTA1 in DNA damage response via modulation of the p21 WAF1-proliferating cell nuclear antigen pathway. J Biol Chem. 2010;285(13):10044-52.

12. Moon HE, Cheon H, Chun KH, Lee SK, Kim YS, Jung BK, Park JA, Kim SH, Jeong JW, Lee MS. Metastasis-associated protein 1 enhances angiogenesis by stabilization of HIF-1alpha. Oncol Rep. 2006;16(4):929-35.

13. Yoo YG, Kong G, Lee MO. Metastasis-associated protein 1 enhances stability of hypoxia-inducible factor-1alpha protein by recruiting histone deacetylase 1. EMBO J. 2006;25(6):1231-41.

14. Weng W, Yin J, Zhang Y, Qiu J, Wang X. Metastasis-associated protein 1 promotes tumor invasion by downregulation of E-cadherin. Int J Oncol. 2014:44(3):812-8.

15. Zhou N, Wang H, Liu H, Xue H, Lin F, Meng X, Liang A, Zhao Z, Liu Y, Qian H. MTA1-upregulated EpCAM is associated with metastatic behaviors and poor prognosis in lung cancer. J Exp Clin Cancer Res. 2015;34:157.
16. Chou DM, Adamson B, Dephoure NE, Tan X, Nottke AC, Hurov KE, Gygi SP, Colaiacovo MP, Elledge SJ. A chromatin localization screen reveals poly (ADP ribose)-regulated recruitment of the repressive polycomb and NuRD complexes to sites of DNA damage. Proc Natl Acad Sci U S A. 2010;107(43):18475-80.

17. Hannafon BN, Carpenter KJ, Berry WL, Janknecht R, Dooley WC, Ding WQ. Exosome-mediated microRNA signaling from breast cancer cells is altered by the anti-angiogenesis agent docosahexaenoic acid (DHA). Mol Cancer. 2015;14(1):133.

18. Liberzon A, Subramanian A, Pinchback R, Thorvaldsdottir H, Tamayo P, Mesirov JP. Molecular signatures database (MSigDB) 3.0. Bioinformatics. 2011:27(12):1739-40.

19. Subramanian A, Tamayo P, Mootha VK, Mukherjee S, Ebert BL, Gillette MA, Paulovich A, Pomeroy SL, Golub TR, Lander ES, et al. Gene set enrichment analysis: a knowledge-based approach for interpreting genome-wide expression profiles. Proc Natl Acad Sci U S A. 2005:102(43):15545-50.

20. Sanjana NE, Shalem O, Zhang F. Improved vectors and genome-wide libraries for CRISPR screening. Nat Methods. 2014;11(8):783-4.

21. Hall JM, McDonnell DP. The estrogen receptor beta-isoform (ERbeta) of the human estrogen receptor modulates ERalpha transcriptional activity and is a key regulator of the cellular response to estrogens and antiestrogens. Endocrinology. 1999;140(12):5566-78.

22. Zhou J, Zhang S, Xue J, Avery J, Wu J, Lind SE, Ding WQ. Activation of peroxisome proliferator-activated receptor alpha (PPARalpha) suppresses hypoxia-inducible factor-1alpha (HIF-1alpha) signaling in Cancer cells. J Biol Chem. 2012;287(42):35161-9.

23. Hannafon BN, Trigoso YD, Calloway CL, Zhao YD, Lum DH, Welm AL, Zhao ZJ, Blick KE, Dooley WC, Ding WQ. Plasma exosome microRNAs are indicative of breast cancer. Breast Cancer Res. 2016:18(1):90

24. Sen N, Gui B, Kumar R. Role of MTA1 in cancer progression and metastasis. Cancer Metastasis Rev. 2014;33(4):879-89.

25. Kang HJ, Lee MH, Kang HL, Kim SH, Ahn JR, Na H, Na TY, Kim YN, Seong JK, Lee MO. Differential regulation of estrogen receptor alpha expression in breast cancer cells by metastasis-associated protein 1. Cancer Res. 2014; 74(5): 1484-94

26. Yao YL, Yang WM. The metastasis-associated proteins 1 and 2 form distinct protein complexes with histone deacetylase activity. J Biol Chem. 2003; 278(43):42560-8

27. Millard CJ, Watson PJ, Celardo I, Gordiyenko Y, Cowley SM, Robinson CV, Fairall L, Schwabe JW. Class I HDACs share a common mechanism of regulation by inositol phosphates. Mol Cell. 2013;51(1):57-67.

28. Pan Y, Wang L, Kang SG, Lu Y, Yang Z, Huynh T, Chen C, Zhou R, Guo M, Zhao Y. Gd-Metallofullerenol nanomaterial suppresses pancreatic Cancer metastasis by inhibiting the interaction of histone deacetylase 1 and metastasis-associated protein 1. ACS Nano. 2015;9(7):6826-36.

Ready to submit your research? Choose BMC and benefit from

- fast, convenient online submission

- thorough peer review by experienced researchers in your field

- rapid publication on acceptance

- support for research data, including large and complex data types

- gold Open Access which fosters wider collaboration and increased citations

- maximum visibility for your research: over $100 \mathrm{M}$ website views per year

At $\mathrm{BMC}$, research is always in progress.

Learn more biomedcentral.com/submissions 